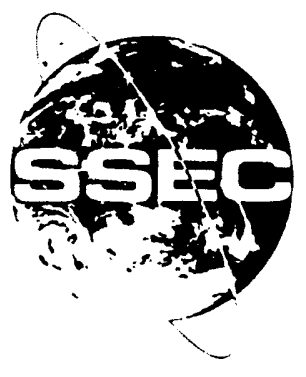

SPACE SCIENCE AND ENGINEERING CENTER

\author{
UNIVERSITY of WISC ONSIN . MADISON \\ 1225 West Dayton Stree: \\ Madison, Wisconsin 53706
}

DOE/ER/61058--1

DE92 000080

Technical Progress Summary

Dept. of Energy Grant DE-FG02-90ER61058

SSEC Project \# 1185

July 30, 1991

Submitted by E.W.Eloranta

The first year of this grant has been devoted to the design and construction of an upgraded version of the University of Wisconsin High Spectral Resolution Lidar (HSRL). The new system incorporates additional data channels to measure depolarization and multiple scattering in the lidar return. Schematic diagrams describing the new configuration are attached to this report. Increases in optical efficiency and receiver aperture, coupled with improvements in the stiffness and the thermal stability of the mechanical system are expected to significantly improve the performance of the instrument. Most components of the system are nearly completed and system integration is about to begin. The HSRL is committed to participate in the NASA FIRE cirrus experiment during November and December of this year. Our progress in completing HSRL subsystems is outlined in the following paragraphs.

\title{
Data System
}

A new data acquisition system has been designed for the HSRL. This will replace a 15 year old photon counting system and the PDP-11 control computer. The new system employes a SUN SparcStation II computer used for the operator interface and data recording. The SUN is connected via ethernet to an Intel i960 controller mounted in a VME card cage. The i960 performs low level system control, network interfacing and data preprocessing. Mounted with the i960 on the VME bus are photon counting and signal averaging cards designed under the support of this grant. The photon counters are designed to accommodate count rates of nearly $1 \mathrm{GHz}$; to date they have been tested at count rates of $250 \mathrm{MHz}$. The signal averaging cards accumulate photon counts from each lidar pulse transmitted in 4,096 successive 100 nsec duration samples. Counts irom a programmable number of laser pulse are averaged into these bins before transfer by the $i 960$ to the SUN for display and recording. Each of the three HSRL photomultiplier tubes(aerosol, molecular and wide-field-of-view data channels) is equipped with a counter module. Two data accumulator modules are provided for each photomultiplier to record results for the two orthogonal polarization components of the lidar return. The network interface programs which provide for communication between the SUN workstation and the 1960 computer have been completed. Software for the control of the HSRL pressure controllers has been written: testing of these routines are just beginning. Programs for data display and storage are now being written for the SUN.

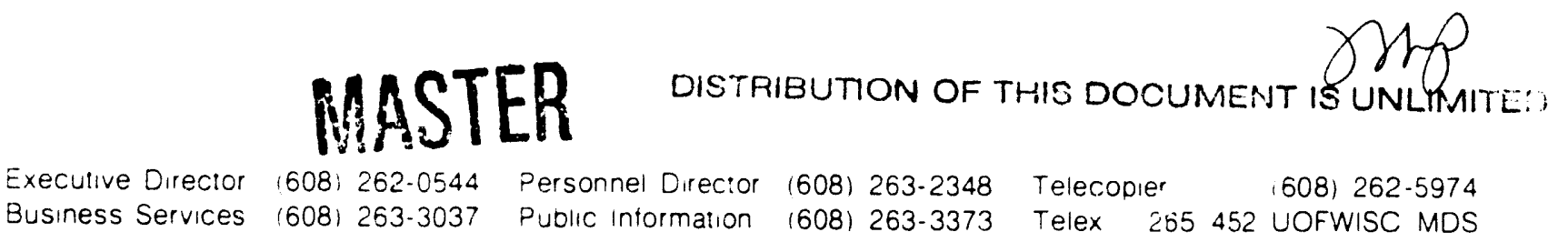




\section{Mechanical Systems}

The mechanical framework for the new HSRL is completed. The temperature control box for the spectrometers is complete. The breadboard for mounting optical components is installed and testing of the temperature control system scheduled to begin the first week of August. Mechanical components for the telescope are currently being fabricated in the Physics department machine shop.

\section{Lidar van}

A semi-trailer van is being outfitted as a mobile laboratory to allow operation of the HSRL in field experiments. This activity is jointly funded by this grant and by the NASA FIRE cirrus experiment. The van is nearly ready for use. Modifications to date include installation of: air ride suspension, a water chiller for the laser, a roof hatch for the telescope, access doors, lights, workbenches, a new floor and partitions to isolate airconditioner and water chiller noise.

\section{Optical systems}

The optical design of the new system is complete. Nearly all optical components including mirrors for the 0.5 meter receiving telescope have been received from vendors. The etalon plates used in the HSRL spectrometer have been recoated in Physics Dept. laboratories. These coatings will allow better rejection of background skylight and thereby improve the the signal to noise ratio in HSRL data. The coatings are now being tested; one plate has a faulty coating and is scheduled for recoating during the first week of August. We anticipate that installation of HSRL optical components will begin on about Aug 15.

\section{Laser Development}

The HSRL uses an injection locked, frequency doubled, Nd-YAG laser as a transmitter. For proper operation, this laser requires that the length of the optical cavity be controlled to within a small fraction of one wavelength of the seed laser. We have designed, constructed and tested a microprocessor based controller to drive the piezo-electric actuators which control the laser cavity length. This controller is now fully functional and has replaced the analog controller supplied by the laser vendor. The new controller increases the percentage of usable laser pulses transmitted by the system and thereby increases the effective output power by approximately $50 \%$. 


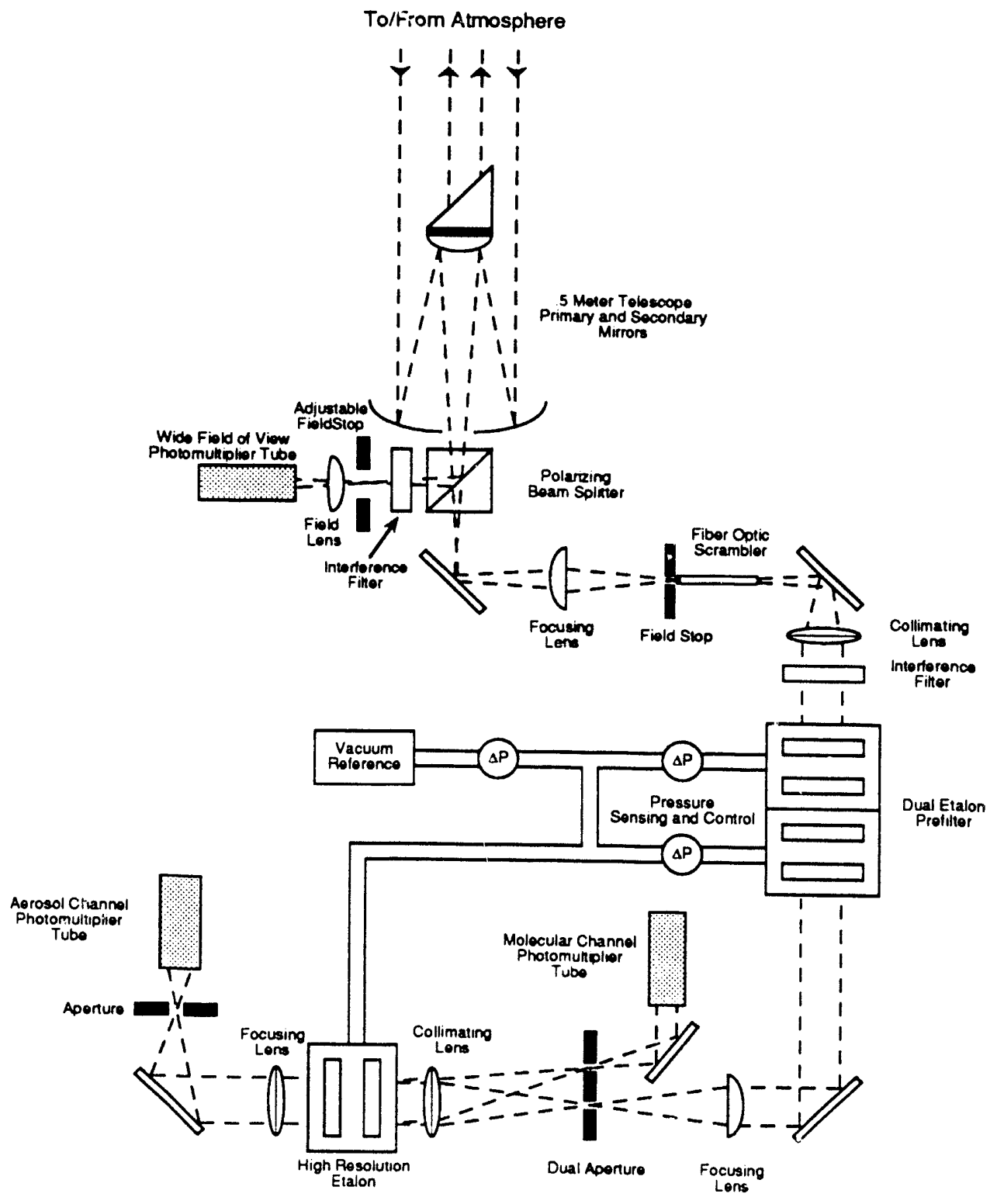

HSRL Receiver 


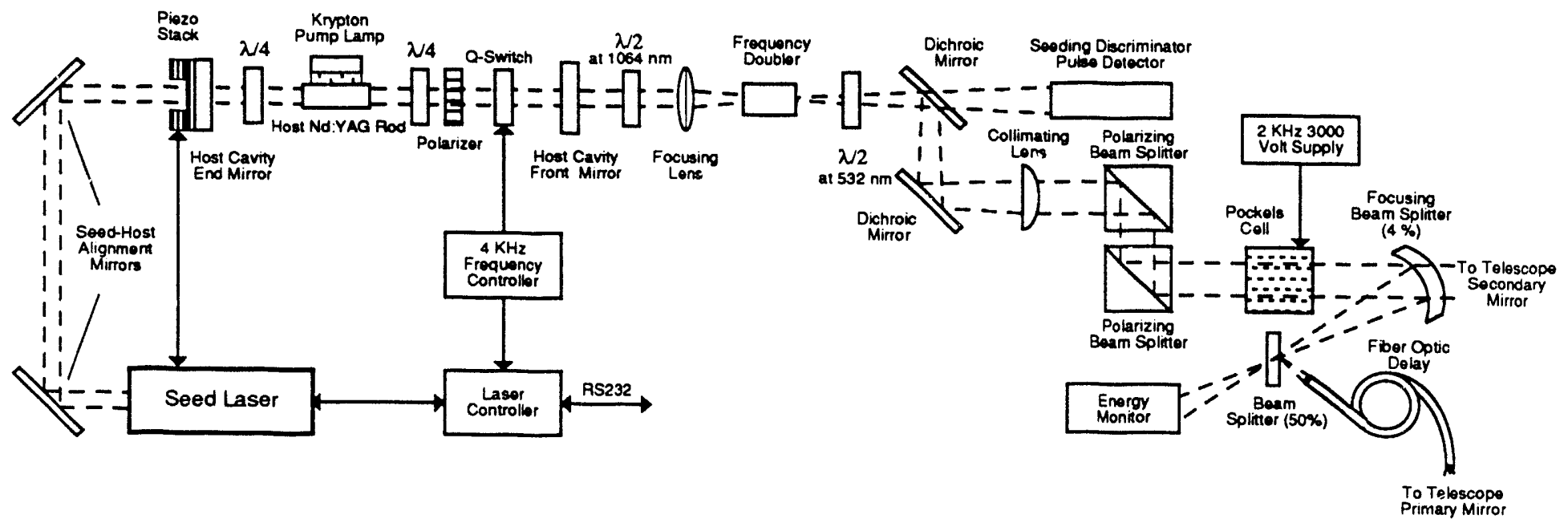

HSRL Transmitter 


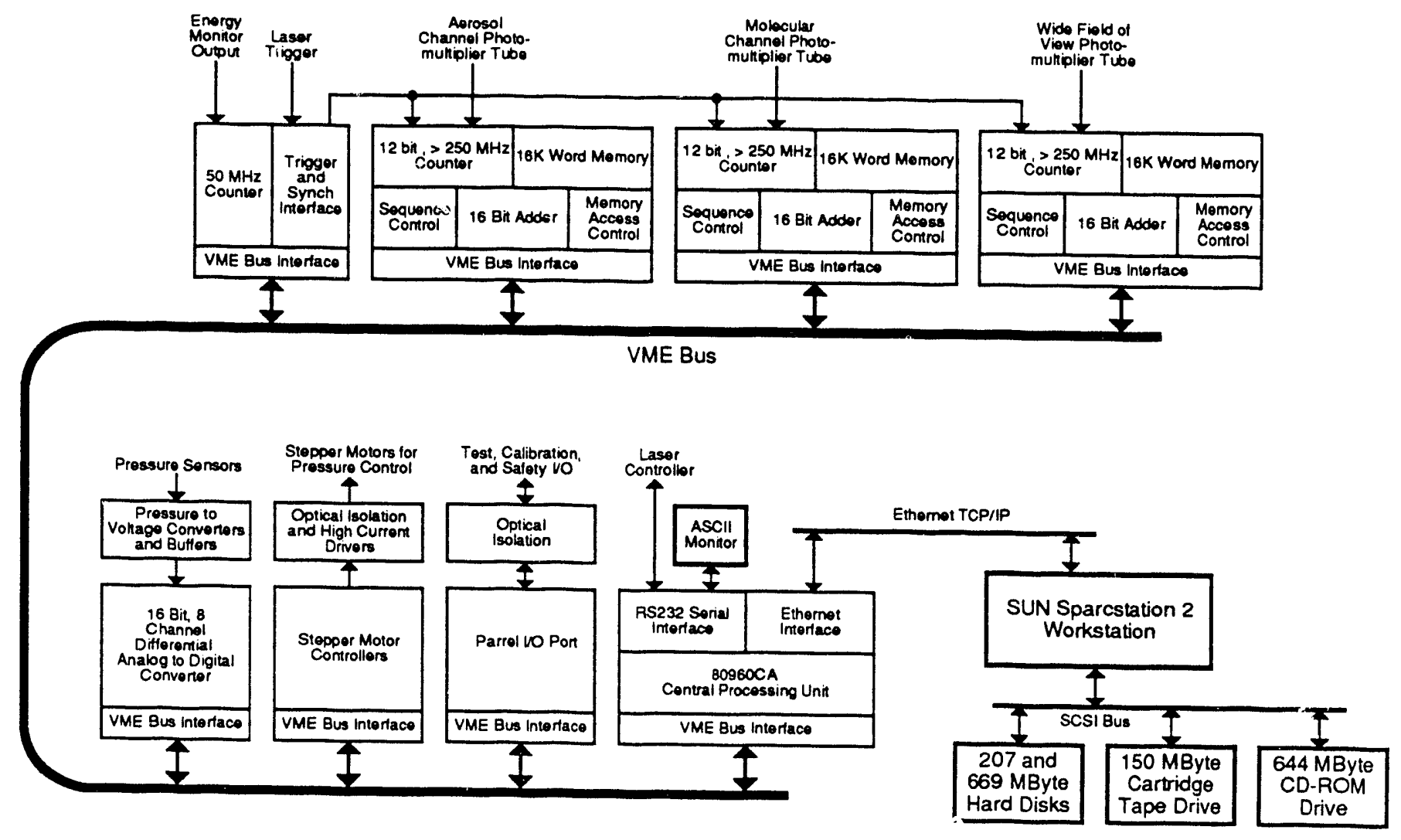

HSRL Data Acquisition System

DISCLAIMER

This report was prepared as an account of work sponsored by an agency of the United States Government. Neither the United States Government nor any agency thereof, nor any of their employees, makes any warranty, express or implied, or assumes any legal liability or responsibility for the accuracy, completeness, or usefulness of any information, apparatus, product, or process disclosed, or represents that its use would not infringe privately owned rights. Reference hereir. to any specific commercial product, process, or service by trade name, trademark, manufacturer, or otherwise does not necessarily constitute or imply its endorsement, recommendation, or favoring by the United States Government or any agency thereof. The views and opinions of authors expressed herein do not necessarily state or reflect those of the United States Government or any agency thereof. 

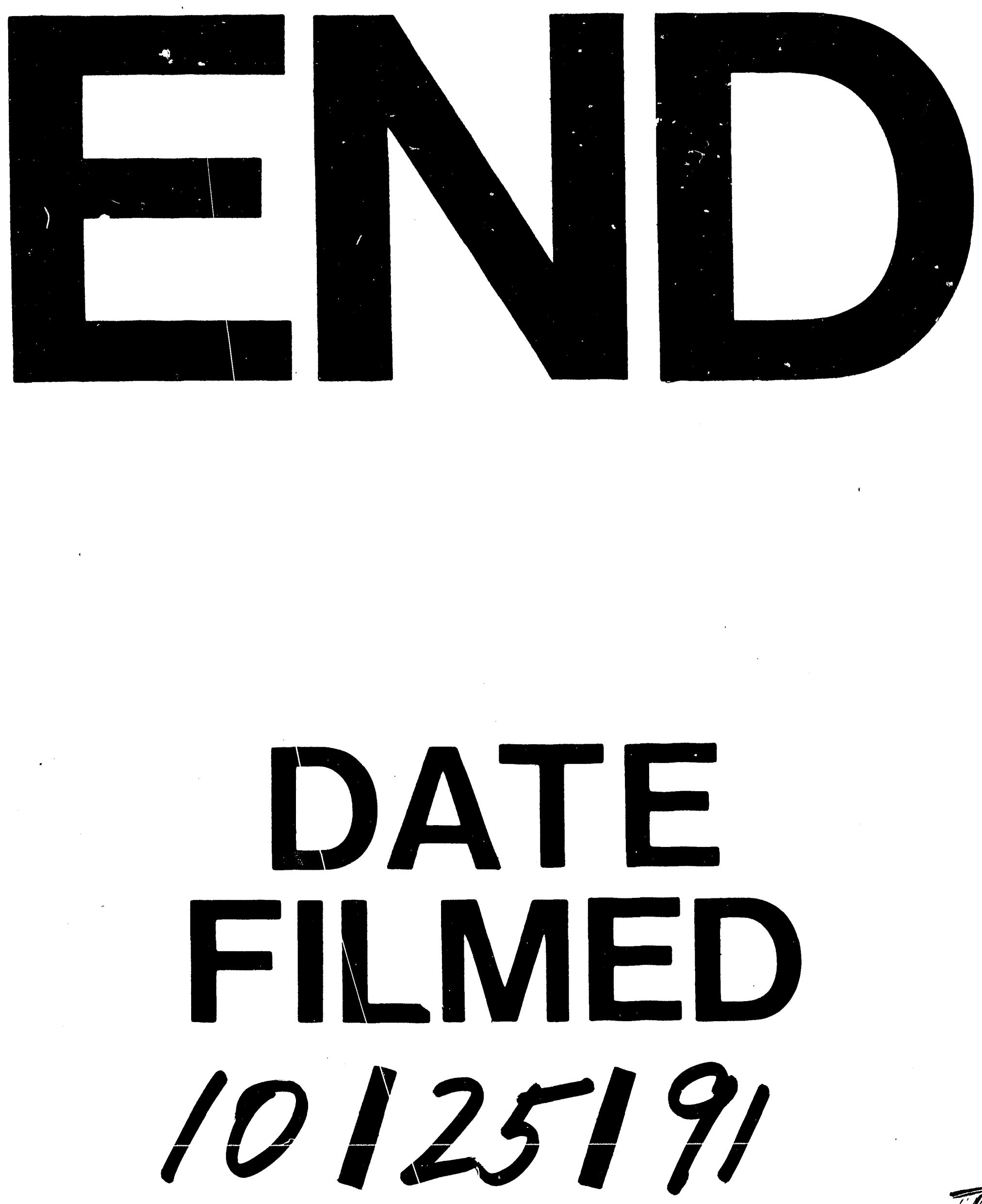
